\title{
The governance of laws of nature: guidance and production
}

\author{
Tobias Wilsch ${ }^{1}$
}

\begin{abstract}
Realists about laws of nature and their Humean opponents disagree on whether laws 'govern'. An independent commitment to the 'governing conception' of laws pushes many towards the realist camp. Despite its significance, however, no satisfactory account of governance has been offered. The goal of this article is to develop such an account. I base my account on two claims. First, we should distinguish two notions of governance, 'guidance' and 'production', and secondly, explanatory phenomena other than laws are also candidates for governance. My goal is to develop a unified account which captures both guidance and production as well as the governance of phenomena, such as essence and logical consequence. The account of governance I develop belongs to the family of modal accounts, which was popularized by David Armstrong, but it also employs essentialist resources. If successful, this modal-essentialist account not only reveals the costs that proponents of governance incur, but it also puts that important notion on a solid theoretical foundation.
\end{abstract}

Keywords Laws of nature - Governing conception · Necessity · Essence · Explanation

\section{Introduction}

Nomic realists claim that some nomic phenomena like laws of nature or dispositions are real: they don't reduce to more fundamental categorical phenomena. A core motivation for nomic realism comes from the claim that only realists can account

Tobias Wilsch

tobias.wilsch@gmail.com

1 Eberhard-Karls University of Tübingen, Philosophisches Seminar, Bursagasse 1, 72070

Tübingen, Germany 
for the laws' governance. Many remain unimpressed by this motivation for nomic realism because they find the notion of governance too elusive to be of theoretical significance. In this article, I will attempt an analysis of governance that puts the notion on a solid theoretical footing.

Most existing characterizations of governance use metaphors. We will see that a closer look at those metaphors reveals a distinction between two different notions of governance. The first notion concerns the guidance aspect of the laws: laws don't merely summarize the facts but guide their development. Tyler Hildebrandt and Barry Loewer expresses that notion of governance as follows:

There is something [...] outside of the mosaic that restricts distributions of properties in the mosaic. (Hildebrandt 2013: 2, emphasis added)

God creates the universe by creating the laws and setting the initial conditions and then lets the history evolve under the direction of the laws. (Loewer 1996:

115 , emphasis added)

Hildebrandt expresses the notion of guidance in terms of "restriction" and Loewer says that laws "direct" the facts. Both are metaphors in need of analysis.

The second notion of governance concerns the way laws account for their instances: governing laws don't merely draw explanatory connections between facts, but they produce them or 'bring them into being'. Helen Beebee expresses this notion of governance in her classic statement of the governing conception:

[It] isn't just that the laws plus current facts entail future facts; rather the laws "make" the future facts be the way they will be... (Beebee 2000: 578)

Beebee's "making" of future facts goes beyond the guidance of laws, as it characterizes the way in which laws bring about facts. Harjit Bhogal and Jonathan Schaffer also suggest that governance involves production:

But, governing is supposed to be some kind of metaphysical production relation that the laws have to instances... (Bhogal 2017: 454)

[Some] non-Humeans think of the laws as not merely entailing but concretely "producing" the associated regularities... (Schaffer 2016: 581)

Beebee, Bhogal and Schaffer suggest that realist laws make or produce their instances, but don't say much about what production might be. These are also metaphors in need of analysis.

I will call the first notion of governance guidance governance and the second production governance. Guidance is about constraining possible avenues for facts, whereas production concerns the way in which facts are created. Since these sorts of characterizations are metaphorical, both guidance and production require explication.

Both notions play important roles in debates about the metaphysical status of nomic phenomena. Guidance concerns the laws' power to support counterfactuals, to establish necessities, and to explain facts. Whereas non-governing laws output deflated modal and explanatory facts, the modal and explanatory outputs of guiding laws are more robust. The desire for more robust modal and explanatory facts 
pushes towards guidance governance. Production relates to the so-called 'oomph' of causation (Schaffer 2004), or more precisely the oomph of the variety of causation that Hall and Ned (2004) calls "production". I will argue below that laws govern in the production sense just in case they establish productive causal explanations. The bold governing theorist might therefore try to establish the productive nature of laws by direct perception of causal relations, or else by introspection of the will: we can simply see that causes produce their effects.

My starting point is then to think of guidance and production as two distinct kinds of governance both worthy of philosophical analysis, although I will ultimately offer a unified analysis that treats production as a special case of guidance. I will, moreover, remain neutral on whether governance in either one of the two senses really obtains. My goal is to explain what governance would be, not to settle whether laws of nature actually govern. This is a modest but important aim. For, we need to know what governance would be to assess the realists' ability to account for it and also to determine the price realists must be willing to pay. On my analysis, nomic realists must pay for governance with primitive necessity in addition to their preferred primitive nomic phenomenon.

I will not limit my discussion of governance to the laws of nature because, as I will explain below, every phenomenon that establishes explanations is a candidate for governance, both in the guidance sense and in the production sense. For example, essences and logical consequence establish metaphysical and logical explanations, and a theory of governance should also say what it would take for these phenomena to govern. Although my focus will be on laws of nature, I will include other 'explanatory phenomena' in the discussion where needed. It will emerge as an advantage of the account that it generalizes beyond laws.

The theory of governance I will develop belongs to the family of modal accounts that goes back at least to David Armstrong (1983). Other approaches to governance also deserve scrutiny, including approaches in terms of metaphysical ground. Since my focus is on developing the modal account, I won't claim that alternative accounts couldn't be developed. But I will explain, after presenting my own account, why ground-based accounts appear less attractive. Since my account of governance is modal, it grants governance only to necessitating laws. But indeterministic laws of nature don't seem to help necessitate their effects. My account of governance, therefore, takes deterministic governance as the paradigm case. I will explain in the final section, how the account can nonetheless be extended to the indeterministic case and what the limitations of that extension are.

Here is how I will proceed. I discuss guidance governance in Sects. 2-8 and production governance in Sects. 9-15. I begin by characterizing guidance-governance as a distinctive 'power to explain' (Sect. 2). I then offer Armstrong's analysis of that power (Sect. 3), extend the analysis to explanatory phenomena beyond laws (Sect. 4), and improve it by distinguishing mere necessitation from 'necessity exertion' (Sect. 5-6). I understand 'necessity exertion' in modal-essentialist terms (Sect. 7), and I identify guidance governance with necessity exertion (Sect. 8).

I turn to production governance in the second part of the article. I will first explain the distinction between productive and systematizing explanations (Sect. 9). Whereas laws seem to produce their instances, essence and logical consequence 
seem to merely systematize them. I then develop a distinction between different 'ways of exerting necessity'. I claim that laws produce, just in case they exert necessity in a 'conditional way' (Sect. 10). I defend this proposal (Sect. 11), analyze different ways of exerting necessity with modal-essentialist resources (Sect. 12), and then generalize the account to other explanatory phenomena (Sect. 13). I highlight advantages of the resulting unified account of governance (Sect. 14) and defend it against objections (Sects. 15, 16).

\section{A power to explain}

Guidance governance might best be understood negatively: what are laws like that do not guide the facts? Humean laws of nature are derived from the 'Humean mosaic', the complete distribution of categorical properties over spacetime. The Humean mosaic displays various regularities, which we express with universal generalizations. According to Humean reductionists, those regularities that play a certain specific role in scientific inquiry are the laws of nature. On David Lewis' (1983) popular best system account, for instance, the regularities that collectively strike the best balance between simplicity and strength have the status of laws.

Humean laws summarize but don't guide the facts. Although this claim is widely accepted, it is not obvious why Humean laws don't exercise guidance governance. To guide the facts is presumably a sort of modal-explanatory activity: guiding laws support counterfactuals, restrict possibilities, and explain facts. But clever Humeans agree that laws do all that. On the standard Humean view, $p$ is nomologically necessary if and because the laws of nature metaphysically necessitate $p$ (Lewis 1973a). Laws are counterfactually stable because of their prominent role in the truth-conditions of counterfactual claims (Ibid). And laws help to explain facts because they also feature in the truth-conditions of claims involving causation and explanation (Lewis 1973b, Lewis 1986).

If Humean laws support counterfactuals, establish necessities, and feature in explanations, why don't they govern, what more could be required? I suggest the following answer. Humean accounts of nomological necessity, counterfactuals, and explanation reduce these phenomena to the laws. And that is all there is to what Humean laws do. There is no sense in which the laws interact with the facts; there is no operation that laws perform to yield facts and explanations. I take the following metaphor to be at the heart of guidance-governance: laws exercise guidance governance just in case they possess a power to explain that goes beyond their featuring in the truth-conditions of modal and explanatory statements.

The laws' power to explain is an operation, something the laws exercise to determine the world to be a certain way. Take, for illustration, the window law, a toy law which says that every perfectly hit window shatters. Understood in a Humean fashion, the regularity 'every perfectly hit window shatters' is necessary because nomological necessity is defined as entailment from the laws. The regularity also 
counts as explained by the law because laws feature in the truth-conditions of explanation-claims. But on the realist governing conception, the window law actively 'engages' with the world to guarantee that all perfectly hit windows shatter, and it is this active engagement that leads to necessity and explanation. ${ }^{1}$ I propose that this distinctive power to explain is what guidance governance consist in, and which an analysis of governance must therefore capture.

\section{Armstrong's proposal}

David Armstrong (1983) was one of the first recent authors to discuss governance. Armstrong analyzes law-truths of the form 'it's a law that $\varphi$ ', or simply L $(\varphi)$, with a higher-order relation he calls Nomic Necessitation that holds between the properties in $\varphi .^{2}$ In his parlance, 'N(F, G)' expresses that Nomic Necessitation relates the universals $\mathrm{F}$ and $\mathrm{G}$. The feature of $\mathrm{N}$ that matters for Armstrong's account of governance is that the material entailment from $\mathrm{N}(\mathrm{F}, \mathrm{G})$ to 'all Fs are $\mathrm{G}$ ' holds with metaphysical necessity. This 'inference' from $\mathrm{N}(\mathrm{F}, \mathrm{G})$ to the corresponding regularity supposedly captures the laws' distinctive power to explain and hence the guidance governance of laws.

Armstrong's account faces the inference problem: why should $\mathrm{N}(\mathrm{F}, \mathrm{G})$ metaphysically necessitate that all Fs are G? More generally, the inference problem arises for nomic realists who aim to explain the modal truth $\square(\operatorname{L}(\varphi) \supset \varphi)$ instead of accepting it as fundamental. Humeans, who analyze the obtaining of a law $\mathrm{L}(\varphi)$ partly in terms of the associated regularity $\varphi$, can explain the modal truth by appeal to the analysis of laws. ${ }^{3}$ Nomic realists, who resist this analysis, on the other hand, must offer an alternative explanation. The inference problem is thus the problem of accounting for the inference from laws to associated regularities. I will argue below that solving the inference problem is the key to guidance governance.

Assuming that Armstrong's account survives the inference problem, it nicely captures the modal aspect of guidance governance, as necessitating laws 'restrict possibilities'. The appeal to necessitation, moreover, illuminates the laws' power to explain: necessitating laws 'force facts into being', so to speak, which is how laws establish explanations. Despite these benefits, however, the account faces two difficulties: it does not generalize to other governing phenomena and it only employs necessitation, which is too weak to capture governance. I present these difficulties in the next two sections and will then develop an updated version of the account that goes well beyond Armstrong's initial idea. The core element that my account preserves is that laws govern partly by necessitating certain facts.

\footnotetext{
${ }^{1}$ For this reason, it does not suffice to say that laws govern if and because they are not grounded in the Humean mosaic. For, if fundamental laws merely featured in the truth-conditions of necessity-claims and explanation-claims in the same way Humean laws do, they would still not 'engage with' the world, and hence wouldn't govern.

${ }^{2}$ I use ' $\varphi$ ' to signify regularities throughout this article. Sometimes ' $\varphi$ ' functions as schematic variable and sometimes as sentence letter. I leave it to the context to disambiguate where it matters.

3 In this vein, Dretske (1977: 251) characterizes regularity theory as "law = universal truth + X", where the $\mathrm{X}$ could, for instance, be filled by the recipe of the best system theory.
} 


\section{Explanatory phenomena}

Laws fall into the broader class of explanatory phenomena, which are phenomena whose core function is to explain facts. Laws of nature feature in (or support ${ }^{4}$ ) causal explanations. In a similar vein, logical consequence features in (or supports) mathematical and logical explanations (Fine 2012; Lange 2014), and essences and metaphysical laws feature in (or support) metaphysical explanations (Dasgupta 2016; Wilsch 2015). To see this, consider the following examples. The logical explanation ' $p v q$ because $p$ ' obtains partly because of the logical entailment from $p$ to $p \vee q$. The metaphysical explanation 'Peter is a bachelor because he is an unmarried male' obtains because of the essence of bachelorhood. Essence and logical consequence are therefore explanatory phenomena.

Laws, essences, and logical consequence are all candidates for guidance governance, as they establish explanations, support counterfactuals, and confer necessity on the facts in their scope. The discussion of Humean laws in Sect. 2 has shown that these features do not suffice for guidance governance; guiding phenomena must also exercise a distinctive power to explain. But we can easily think of essences and logical consequence as exercising such a distinctive power and thus as guiding the facts. An account of guidance governance should therefore be applicable to these phenomena. Even if it may turn out that not all explanatory phenomena govern, I prefer an account of governance that explains for each explanatory phenomenon what it would take for that phenomenon to govern.

Armstrong's account of governance is too narrow as it stands because it does not apply to explanatory phenomena other than laws. Armstrong employs a higher-order universal $\mathrm{N}$ to act as the laws of nature, but he does not introduce corresponding entities for essence, metaphysical laws, or logical consequence. Since it is not clear what the ontological correlates of essence and logical consequence would even be, it is difficult to generalize the account beyond laws. ${ }^{5}$

One might respond, in defense of Armstrong, that only laws of nature govern because governance is a diachronic activity: laws govern because they concern the development of facts over time. However, this strikes me as unnecessarily narrow. Governance must perhaps occur along an 'axis'. But every kind of explanation corresponds to an axis. Metaphysical laws and essences govern facts along the axis of fundamentality, from the more to the less fundamental, and logical consequence might govern facts along the axis of logical complexity. At any rate, the core idea of guidance governance, viz. the execution of a distinctive power to explain, is applicable to every explanatory phenomenon.

\footnotetext{
${ }^{4}$ If $\mathrm{p}$ causally explains $\mathrm{q}$, then $\mathrm{L}(\varphi)$ either features together with $\mathrm{p}$ in the causal explanation of $\mathrm{q}$, or $\mathrm{L}(\varphi)$ strictly speaking does not explain $\mathrm{q}$ at all, but instead explains the fact that $\mathrm{p}$ sufficiently explains $\mathrm{q}$. I will return to this view in Sect. 9.

5 Jonathan Lowe (2008: 39) argues that essences cannot be entities due to a regress of essenceexplanations.
} 


\section{Necessity exertion}

There is an easy way to extend Armstrong's view to other explanatory phenomena. We can deny that the higher-order relation $\mathrm{N}$ has intrinsic relevance for governance; what matters instead is that $\mathrm{L}(\varphi)$ necessitates $\varphi$, whether $\mathrm{L}$ has an ontological correlate or whether $\mathrm{L}$ is a primitive bit of ideology. We can then generalize Armstrong's account of governance as follows: laws, essence, or logical consequence govern just in case the following associated Entailment principle holds (read ' $\mathrm{E}(\mathrm{x})(\mathrm{P})$ ' as 'it is essential to $\mathrm{x}$ that $\mathrm{P}$ '; capitalized letters are schematic variables, lower case letters are sentence letters throughout):

$\begin{array}{ll}\text { Entailment (L) } & \square(\mathrm{L}(\varphi) \supset \varphi) \\ \text { Entailment (E) } & \square(\mathrm{E}(\mathrm{x})(\mathrm{P}) \supset \mathrm{P}) \\ \text { Entailment ( }(\vDash) & \square((\vDash \mathrm{P}) \supset \mathrm{P})\end{array}$

On this updated Armstrongean view, guidance governance coincides with necessitation. More precisely, a phenomenon governs just in case it can be expressed by a sentential operator and it necessitates the truths in its scope.

This simple update doesn't work, however, because Entailment principles do not suffice for governance. To see that several non-governing phenomena also feature in Entailment principles, consider the following principles for knowledge (' $\mathrm{K}$ '), fundamentality ('F'), and truth (' $\mathrm{T}$ '):

$$
\begin{array}{ll}
\text { Entailment (K) } & \square(\mathrm{K}(\mathrm{P}) \supset \mathrm{P}) \\
\text { Entailment (F) } & \square(\mathrm{F}(\mathrm{P}) \supset \mathrm{P}) \\
\text { Entailment (T) } & \square(\mathrm{T}(\mathrm{P}) \supset \mathrm{P})
\end{array}
$$

Knowledge, fundamentality and truth don't govern despite necessitating the truths in their scope. For, governance is a power to explain and knowledge, fundamentality and truth don't explain. (Try the explanation " $p$ because $p$ is true"!) The general upshot I draw from these examples is that necessitation is too weak a relation to capture governance. If we wish to preserve the core of Armstrong's account, then governance requires a stronger connection with necessity. I will therefore say that governing phenomena not only necessitate, but that they exert necessity on facts; they exert a modal force by which they render truths necessary and establish explanations. The idea of necessity exertion suits the intent behind Armstrong's position, but has not received a satisfactory analysis. This is what I turn to next.

\section{Against fundamental necessitation}

What distinguishes 'mere necessitation' from necessity exertion? I suggest that the answer lies in the solution to the inference problem, which asks for an explanation of Entailment (L). More specifically, I claim that whether a phenomenon merely 
necessitates, or whether it exerts necessity, depends on the metaphysical grounds of the Entailment principle it features in. ${ }^{6}$

To appreciate this point, consider the Humean explanation of Entailment (L). On the Humean view, Entailment (L) follows from the analysis of laws. Humeans are regularity theorists, which means that they accept that for $\mathrm{L}(\varphi)$ to obtain is in part for the regularity $\varphi$ to obtain, and hence that ' $L(\varphi) \supset \varphi$ ' follows logically from the laws' real definition or essence (where $\mathrm{X}$ specifies the conditions that lawful regularities must satisfy):

$$
\text { Regularity Theory } \quad \mathrm{E}(\mathrm{L})(\mathrm{L}(\varphi) \equiv \varphi \& \mathrm{X})
$$

Humean laws necessitate the regularities in their scope because, intuitively put, the regularity is a 'metaphysical prerequisite' for the law: the regularity must be in place 'before' it can acquire the status of law. A promising suggestion is, therefore, that a necessitation fact constitutes necessity exertion only if that which is necessitated is not a prerequisite for that which does the necessitating. In our case, this means that the laws' necessitating the regularity cannot be due to the regularity's being a prerequisite for the law.

Perhaps we should then say that Entailment (L) expresses necessity exertion because it has no grounds. However, I find it attractive to deny that any necessitytruth of the form of $\square$ (p) is fundamental. Such a ban on fundamental necessitytruths is attractive for at least two reasons. The first reason derives from the similarity between necessity-truths and universal generalizations: $\square$ (p) says that $\mathrm{p}$ obtains in every possibility. Distribution patterns across possibilities cry out for explanations in the way distribution patterns in the actual world cry out for explanation. We should therefore explain them if we can. The second reason to reject fundamental necessity-truths it that there are systematic grounding-relationships between necessity and various hyperintensional source-phenomena. We can easily find grounds that feature essence, logical consequence, or laws for most necessity-truths. This suggests that necessity is generally downstream from these hyperintensional phenomena. ${ }^{7}$

If these reasons are convincing, Entailment (L) should not be considered a fundamental fact, and thus a different explanation is needed. I will provide an alternative explanation next that, as I will claim, holds the key to necessity exertion. Readers who remain unimpressed by arguments against fundamental necessitytruths can rebuild the following accounts of necessity exertion and governance in terms of fundamental necessities. I will explain in footnotes 9 and 19 how that version of the account can be developed.

\footnotetext{
${ }^{6}$ I am not the first to suggest a connection between the inference problem and governance. Jonathan Schaffer (2016) argues that nomic realists should take the inference from laws to regularities to be axiomatic, and he claims that this captures the governance of laws. Schaffer's notion of 'governance' is quite different from mine as he applies it to factive phenomena like knowledge. My account of guidance governance can, however, be viewed as an elaboration of Schaffer's view.

7 Hale (2002) argues with what he calls "Blackburn's dilemma" that certain necessity-truths are fundamental, namely those concerning the necessity of essence-facts. But even if that argument was sound, it would do little to justify the fundamentality of $\square(\operatorname{L}(\varphi) \supset \varphi)$.
} 


\section{Modal essences}

I propose a different explanation of Entailment (L). I will say that Entailment (L) is encoded in the essence of laws:

$$
\text { Essential Factivity (L) } \quad \mathrm{E}(\mathrm{L})(\square(\mathrm{L}(\varphi) \supset \varphi))
$$

Essence-truths of this form allow us to avoid fundamental necessity-truths because, as Martin Glazier (2017) argues convincingly, essences explain the truths in their scope. If we use Essential Factivity to explain $\square(\mathrm{L}(\varphi) \supset \varphi$ ) we avoid fundamental necessities. ${ }^{8}$

We can generalize this use of essence to characterize necessity exertion: roughly, a phenomenon $\mathrm{S}$ exerts necessity if a suitable modal fact that features $\mathrm{S}$ belong to S's essence. According to this view, merely necessitating phenomena like knowledge have an essence that contains a material conditional like $K(p) \supset p$, while essences of necessity-exerting phenomena like (let's assume) laws, essence, and logical consequence contain strict implications:

$$
\begin{array}{ll}
\text { Essential Factivity (L) } & \mathrm{E}(\mathrm{L})(\square(\mathrm{L}(\varphi) \supset \varphi)) \\
\text { Essential Factivity }(\mathrm{E}) & \mathrm{E}(\mathrm{E})(\square(\mathrm{E}(\mathrm{x})(\mathrm{P}) \supset \mathrm{P})) \\
\text { Essential Factivity }(\vDash) & \mathrm{E}(\models)(\square((\models \mathrm{P}) \supset \mathrm{P}))
\end{array}
$$

To further motivate the proposal, I note first that these proposed essence-truths are modal essences which feature the necessity operator: $\mathrm{E}(\mathrm{x})(\ldots \square \ldots)$. I suggest that modal essences are a rare distinction had only by explanatory phenomena. ${ }^{9}$ Ordinary phenomena such as material bodies and categorical properties and relations like truth and knowledge don't have modal essences. It is essential to you, for instance, that you are human, but it is not essential to you that you are necessarily human. That you are necessarily human is a consequence of your essence; it is not part of your essence.

It might be responded with Kit Fine's (1994: 1) principle that "if a given property is essential, then so is the property of essentially having that property". Thus, if I am essentially human, it is also essential to me that I am essentially human. And since my necessary humanity follows from my essential humanity, it should also be essential to me that I am necessarily human. But the notion of essence I will use throughout this article is a notion of basic essence (or 'constitutive essence' in Fine 1995). Basic essence is not closed under entailment and Fine's principle, moreover, seems more plausible when applied to derivative (or 'consequential') essence.

\footnotetext{
${ }^{8}$ Why not solve the inference problem with the simpler non-modal essence $\mathrm{E}(\mathrm{L})(\mathrm{L}(\varphi) \supset \varphi)$ ? This essence-claim arguably entails that either $\varphi$ is a partial ground of $L \varphi$ or that $L \varphi$ is a sufficient ground for $\varphi$. See Wilsch (2018) for a defense of this essence-ground principle. The first disjunct amounts to the regularity-theoretic claim that $\varphi$ is a metaphysical prerequisite for $L(\varphi)$, and would thus not sustain necessity exertion. The second disjunct amounts to one of the ground-based accounts of governance that I discuss in Sect. 15 below. I kindly refer the reader to that section for objections to the proposal.

9 Foes of essence and fans of fundamental necessities might instead try the view that to exert necessity an explanatory phenomenon must feature not in an essential but in a fundamental necessity-truth.
} 
I claim that those phenomena have basic modal essences (I will drop 'basic' henceforth) which can be said to exert necessity, a modal force, on the facts: to exert necessity is to have a suitable modal essence. I say a 'suitable' modal essence for two reasons. First, although the modal essences I will use throughout this article take the form of necessitation, I am open to the idea that modal essences of a different form characterize varieties of governance that I do not capture here. ${ }^{10}$ Secondly, there are some notable exceptions to the rule that bearers of modal essences exert necessity. One such exception concerns necessity itself, which presumably has a modal essence, but which does not exert itself. Another exception are gerrymandered phenomena, which are partly defined-up in terms of necessitytruths. I discuss exceptions of this sort in more detail in Wilsch (2017) but I will ignore them here as they are tangential to our topic of governance. ${ }^{11}$

\section{Guidance governance}

Let me retrace my steps. I have argued that a necessitation-based account of governance should generalize to all explanatory phenomena, in the sense at least that it explains what it would take for any such phenomenon to exercise guidance governance. I have also argued that we must distinguish necessity exertion from mere necessitation because necessitation is weaker than governance. I have then suggested that necessity exertion is to be analyzed in terms of modal essences, because this way we avoid fundamental necessity-truths and because modal essences are arguably distinctive of explanatory phenomena. This brings me to the conclusion of the first part of this paper: to guide the facts is to have a suitable modal essence.

Our analysis of governance has the advantage that it provides a link between governance and explanation. As was also Armstrong's original idea, governing phenomena explain, precisely because they exert necessity on facts. If laws of nature, for instance, exerted necessity, a modal force, on the regularities in their scope, they would force those regularities into being, and would thereby explain them. In slogan form, laws explain facts because they exert necessity on them. And in more sober words, modal essences feature in the grounds of explanations.

A second advantage of the account is that it generalizes beyond laws. It allows for multiple explanatory phenomena to exert guidance governance, and it provides a unified treatment of their respective powers to establish explanations. We could hold, for instance, that laws, essence, and logical consequence all explain for the same reason: they all have modal essences and therefore exert necessity on facts.

\footnotetext{
${ }^{10} \mathrm{I}$ am open, in particular to the idea that some phenomena $\mathrm{S}$ govern because their modal essence is of the shape $\mathrm{E}(\mathrm{S})(\mathrm{Sp} \supset \square \mathrm{p})$. I take this sort of modal essence to characterize a kind of non-productive guidance governance, if it characterizes a kind of governance at all.

11 Are modal essences compatible with the contention from Sect. 4 that explanatory phenomena are pure ideology without ontological correlates? I think so, as $\mathrm{E}(\mathrm{x})(\mathrm{p})$ carries no ontological commitment to the bearer-position $\mathrm{x}$, since we can give at least partial real definitions of non-existing phenomena like (as the case may be) platonic universals or God, and of mere ideology such as necessity and logical operators.
} 
We might resist this unified treatment for phenomena whose explanatory power is entirely different; but even if we deem, say, logical consequence to establish explanations in a different way, the account still provides a unified approach to the remaining explanatory phenomena.

Although I prefer a unified approach to explanatory phenomena, I insist that there are also important differences between them. I am not proposing that laws, essence, and logical consequence work in just the same way! One important difference between laws and other explanatory phenomena concerns what I have called 'production governance'. I will argue in the second part of the article that to produce facts, rather than to systematize them, is to exert necessity in a particular way. Different explanatory phenomena might exert necessity in different ways.

It might be objected to the proposed account that guidance governance comes at the cost of a primitive notion of necessity. For, if necessity features in the essence of laws, essence, and logical consequence, then necessity can, on pain of circularity, not be defined in terms of these phenomena. But there don't seem to be other phenomena that necessity can be defined with. If governance requires modal essences, it therefore commits us to the view that necessity is a primitive phenomenon, a "joint in nature" (Sider 2012: ch. 12; Wilsch 2017). Nomic realists who endorse guidance governance must pay a surprising surcharge: they must combine their preferred primitive nomic phenomenon with a primitive notion of necessity. ${ }^{12}$

Modal primitivism can be avoided if essence doesn't have a modal essence. Metaphysical necessity might then feature in the essence of laws while also being defined with essence (perhaps à la Fine 1994). But if we use modal essences for a unified approach to guidance governance that includes essence as a guiding phenomenon, this avenue is closed. Nomic realists who endorse a unified necessitation-based approach to guidance governance must therefore combine their primitive explanatory phenomena with a primitive notion of necessity. One might of course reject such views on grounds of metaphysical extravagancy. But it might also be just the right price to pay for governance. I will argue that this price buys us both guidance and production, which might be worth the expense.

\section{Productive explanations}

We saw earlier that "governance" is used in at least two different ways to mean guidance and production. I will now turn to production governance. The goal of this section is to clarify production and to explain its significant. I will argue that we should distinguish productive from what I call systematizing explanations, and that a

\footnotetext{
12 Or they could define their nomic notion in terms of necessity? I am skeptical as defining hyperintensional notions from modal ones has proven very difficult (Fine 1994, 2001).
} 
phenomenon exercises production governance just in case it establishes productive explanations.

To better understand production, it will help to examine non-productive explanations. One potential case of non-productive explanations is that of causal explanations in the Humean framework. Since Humean laws are grounded in regularities, they are also grounded in the instances of those regularities. But laws are also involved in the causal explanation of their instances. So, laws help to causally explain facts that are metaphysically prior to the laws. There is then a real sense in which the explained fact was "already there" prior to its own explanation. I agree with Tim Maudlin (2007: 175) that "an item cannot be the ontological ground of its own production". Humean explanations are therefore not productive.

There is a popular argument to the effect that Humean explanations are no explanations at all. The argument rests on the diagnosis of a vicious cyclical structure: if laws explain their instances, which, according to the Humean, help to explain the laws, explanation runs in a circle. Since explanation is never cyclical, the argument goes, there cannot be any Humean explanations (Lange 2013). But if Humean explanation is not a case of non-productive explanation after all, we might begin to wonder whether I am trying to draw a distinction where there is none to be drawn.

I doubt, however, that the attack on Humean explanation is successful because Humeans can deny that laws explain their instances. Instead of 'featuring in' causal explanations, Humeans can take laws to merely ground causal explanations. Strictly speaking, for instance, the window law does not explain the window's shattering; the law only explains why the rock-impact sufficiently explains the windowshattering. Since the law does not causally explain the shattering, the shattering metaphysically explains the law without circularity. ${ }^{13}$

I thus think that Humean explanations provide a case of non-productive explanations. But there are also other plausible candidates for non-productive explanations, including mathematical and logical explanations such as the following:

- $2+3=5$ because of the Peano Axioms

- $\mathrm{p} v \mathrm{q}$ because $\mathrm{p}$

Individual arithmetical truths are ultimately explained by arithmetical axioms, and logically complex truths are ultimately explained by logically simple truths. We could think of mathematical and logical explanation as productive: the mathematical axioms or the atomic truths generate new layers of truths. But on the natural alternative view, logical consequence systematizes an arithmetical or logical mosaic that was 'already given'. If we take causal explanations to be productive, while maintaining that mathematical and logical explanations are systematizing, we can

\footnotetext{
13 Skow (2016: ch. 4) defends the claim that laws do not causally explain in detail. Lange (2018) claims that this does not make the circularity go away, but I find his reasoning unconvincing. However, Loewer (2012), Miller (2015) and others offer different defenses of Humean explanations, which would also serve my purpose.
} 
thereby capture the thought that a certain explanatory 'oomph' is distinctive to causation. We should at least be able to state that view.

The need to distinguish productive and systematizing explanation can thus be motivated by appeal to the possibility of Humean explanations and by the contrast between causal and certain non-causal explanations. "Systematizing explanations", I should add, is a fairly broad label, as both Humean laws and more substantive laws that exercise only guidance governance can establish systematizing explanations. The difference between them is that only one is brought about by a distinctive power to explain. The distinction between productive and systematizing explanations yields a related distinction between productive and systematizing phenomena. For, the question of whether laws, or any other explanatory phenomenon, govern in the production sense, depends on whether they establish productive explanations. These distinctions are, however, admittedly elusive. My goal is to make them precise.

\section{Ways of exertion}

When does a phenomenon establish productive explanations? I return to our analysis of guidance governance to answer this question. The conclusion of the previous part has it that to exercise guidance governance is to exert necessity on facts. The idea I will develop in what follows is that necessity can be exerted in different ways, and that one way of exerting necessity amounts to production, while a different way of exertion amounts to systematization. Since necessity exertion constitutes guidance governance, the resulting account will treat production as a special case of guidance. I will make free use of the exertion metaphor in this section and the next, but in Sect. 12, I will account for it with the modal essences from Part I.

To capture production and systematization with the exertion metaphor, I distinguish between direct and conditional exertion of necessity. This distinction concerns the 'target' of the exertion. If laws of nature exert directly, then the target of exertion is the regularity in their scope. I will thus say that directly exerting laws exert necessity 'on' the regularity in their scope. If, on the other hand, laws exert conditionally, then the target of exertion is a putative causal effect. But since laws exert necessity on an effect only conditional on the obtaining of the associated cause, I call that way of exertion 'conditional'.

Consider an example that illustrates this distinction. The window law exerts necessity either on the regularity that every perfectly hit window shatters, or on individual shattering events. The former way of exertion is direct. But the latter kind of exertion is conditional, as the law exerts necessity on the putative shattering only on the condition that the window is perfectly hit. We will see below that laws exert either directly or conditionally but not both.

Direct and conditional exertion of necessity lead to two different kinds of explanation. I will assume that whenever necessity is exerted on some putative fact, 
that fact comes into existence as a result of the exertion. So, if a law exerts necessity directly on the regularity in its scope, then that regularity obtains. The most fundamental explanation established by a directly exerting law, $L(\varphi)$, is therefore of the form ' $L(\varphi)$ explains $\varphi$ '. (I say the 'most fundamental' explanation because, as we will see, other explanations can be derived from it.) In slogan form, direct exertion fundamentally leads to explanations of regularities.

If we assume, on the other hand, that laws exert necessity conditionally on their instances, then the most fundamental explanations established by laws are causal explanations of the form ' $p$ explains q'. If the window law, for instance, exerts necessity on individual window-shatterings conditional on the fact that the particular window was perfectly hit, then the immediately resulting explanation takes the following form: 'Window1 is perfectly hit explains that Window1 shatters'. In slogan form, conditional exertion fundamentally leads to causal explanations.

I will in what follows defend the following constitutive claim about the production governance of laws: laws of nature exercise production governance just in case they exert necessity conditionally and thus fundamentally establish causal explanations. I also endorse the complementary claim that laws of nature establish systematizing explanations if they exert necessity directly and thus fundamentally establish explanations of regularities. I will next defend the constitutive claim about production governance, and I will then show how direct and conditional exertion can be analyzed with modal essences.

\section{Production as conditional exertion}

In the first step of the argument for the constitutive claim, I show that if laws exert necessity directly, then they don't establish productive explanations. Assume then that laws exert necessity directly and hence that they fundamentally establish explanations of the regularities in their scope. How do laws establish causal explanations on this view? Consider a concrete instance of this question: How does the window law establish the causal explanation of 'Window1 shatters' if it fundamentally explains that every perfectly hit window shatters? The natural response to this question is that the established regularity together with the fact that Window1 is perfectly hit accounts for the fact that Window 1 shatters.

To be more precise, once the regularity is explained by the law, we can generate causal explanations by subsuming instances under the regularity. One very simple conception of subsumption is the deductive-nomological model, on which we deduce the effect from the lawful generalization and its cause:

1. All perfectly hit windows shatter [lawful regularity]

2. Window 1 is perfectly hit [assumption]

3. Window 1 shatters $[1,2]$ 
I do not mean to suggest that the deductive-nomological model does justice to the complicated derivation of causal explanations from lawful regularities. Various more complex approaches to this task, from unificationism to causal modelling, are available in the literature. What all these approaches have in common is that once suitable general truths are established as lawful, individual causal explanations can be derived from them. Assuming then that one of the approaches works, we can conclude that when a law explains a regularity, that regularity may then yield explanations of causal effects.

So, if laws fundamentally establish explanations of regularities, then causal explanations follow as a derivative consequence. The crucial point I now wish to make is this: if causal explanations are derived from subsumption under regularities, then they are not productive. The reason for this is that regularities are grounded in their instances and that on the subsumption view, regularities support the causal explanation of their instances. ${ }^{14}$ Since it follows from these assumptions that causal effects are grounds of their own explanation, causal explanation by subsumption is not productive. For, recall Maudlin's insight that nothing can be "the ontological ground of its own production". ${ }^{15}$

If laws exert necessity directly, then they establish causal explanations by subsumption. Since such explanations are not productive, directly exerting laws are not productive but systematizing. This is the first step of the argument. It remains to show that if laws exert necessity conditionally, then the explanations they establish are productive. Let us thus assume that laws exert necessity conditionally on their instances, and hence that they fundamentally establish causal explanations. On this view, the window law is a kind of input-output mechanism, as it sits there, poised to establish causal explanations. When a particular window is perfectly hit, the law conditionally exerts necessity on the putative fact that this window shatters. This results in explanations of the form 'Window 1 shatters because it is perfectly hit'. If we also assume that the window law exerts necessity consistently across time, it follows that whenever a window is perfectly hit that window shatters. Explanations of regularities are thus derived from the laws' power to establish causal explanations.

We can now see that direct and conditional exertion of necessity compete. If laws exert directly, then explanations of regularities are more fundamental than derived causal explanations. And if laws exert necessity conditionally, then causal explanations are more fundamental than derived explanations of regularities. I have shown that on the first option, causal explanations are not productive, and it is

\footnotetext{
${ }^{14}$ Bhogal (2017) and Marshall (2015) deny that regularities are grounded in their instances. I explain in Sect. 15 that my view has the advantage that it can accept grounding orthodoxy.

15 There is an interesting potential exception to this claim, as one might think that "p explains q" is always partly grounded in q, - at least in cases of indeterministic explanations. But I think that there is a difference between $q$ featuring as a mere cap-stone of the explanation and q being a ground of any of the other grounds of "p explains q". Thanks to an anonymous referee for this worry.
} 
therefore a natural suggestion that the second option suffices for production: laws exercise production governance just in case they exert necessity conditionally. This is the constitutive claim.

\section{The modal essence account}

It is now time to tame the metaphors of direct and conditional exertion of necessity, which I have been using freely throughout this part. In Part I, I have introduced modal essences of the form $\mathrm{E}(\mathrm{S})(\square(\mathrm{S}(\mathrm{P}) \supset \mathrm{P}))$ to express that the phenomenon $\mathrm{S}$ exerts necessity. The claim I defend in this section is that we can capture direct and conditional exertion by specifying suitable contents of modal essences. I begin with the modal essence of laws of nature and will then generalize the resulting account to other explanatory phenomena.

I analyze direct exertion of necessity with the already familiar principle $\square(\mathrm{L}(\varphi) \supset \varphi)$. Laws of nature exert necessity directly on the regularities in their scope just in case they have the following modal essence:

$$
\text { Essential Factivity (L) } \quad \mathrm{E}(\mathrm{L})(\square(\mathrm{L}(\varphi) \supset \varphi))
$$

Conditional exertion of a necessity is more difficult to express, as it requires an unfamiliar conception of laws. The standard expression for laws is the monadic sentential operator 'It is a law of nature that _'. 'Being a law' is then naturally understood as signifying a property of facts or propositions. But we can also think of laws as functions mapping possible states of the world to possible (later) states. I introduce the dyadic operator $\mathrm{L}\left({ }_{-},{ }_{-}\right)$to express laws conceived of as functions. The sentence ' $\mathrm{L}(\mathrm{p}, \mathrm{q})$ ' says that laws map $\mathrm{p}$ to $\mathrm{q}$. The intended reading of ' $\mathrm{L}(\mathrm{p}, \mathrm{q})$ ' is non-factive and thus has a hypothetical element: the laws would determine $q$ based on $\mathrm{p}$.

With the dyadic notion in place, we can formulate the following modal essence:

$$
\text { Essential Polyadic Factivity (L) } \quad \mathrm{E}(\mathrm{L})(\square((\mathrm{L}(\mathrm{P}, \mathrm{Q}) \& \mathrm{P}) \supset \mathrm{Q}))
$$

What the two modal essences have in common is a relation of strict implication or 'necessitation' in the scope of essence. As I proposed in the previous part, this suffices for necessity exertion. We can read the consequent of the embedded conditional as the 'target' of the exertion, and the phenomenon in the antecedent as the exerting phenomenon. Essential Factivity thus expresses that laws exert necessity on the truth $(\varphi)$ in their scope, and Essential Polyadic Factivity expresses that laws exert necessity conditionally on its instances (q), namely conditionally on the obtaining of the associated cause (p).

The appeal to modal essences explains why every phenomenon that governs in the guidance sense either produces or systematizes, but not both. This is because the notion of essence that I am employing is a notion of basic essence which is plausibly taken to be minimal in the sense that it does not contain inter-derivable principles. 
The principles $\square(\mathrm{L}(\varphi) \supset \varphi)$ and $\square((\mathrm{L}(\mathrm{P}, \mathrm{Q}) \& \mathrm{P}) \supset \mathrm{Q})$ are inter-derivable (and so are corresponding principles for other explanatory phenomena). ${ }^{16}$ Laws therefore exert either directly or conditionally.

It may be objected to the account of direct and conditional exertion that the polyadic notion of a law is defective, perhaps because the functional conception of laws is flawed. This point, however, is not an objection to the account. It just means that we might be constrained in our choice of modal essences. If the polyadic notion of law is indeed defective, then laws don't exert necessity conditionally (and thus do not exercise production-governance). ${ }^{17}$

We now have all the ingredients for an account of the production governance of laws. I have argued that laws exercise production governance just in case they exert necessity conditionally. Conditional exertion is then understood in terms of modal essences: laws exert necessity conditionally just in case they are characterized by Essential Polyadic Facticity (L). Thus, the official account says that for laws to govern in the production sense is for them to have the modal essence Essential Polyadic Facticity (L).

With the account of production governance on the table, we might wonder whether it suffices to capture the "oomph" of causation. Essential Polyadic Factivity (L) says that laws essentially conditionally necessitate effects. Does this essential modal "enforcing" really capture production in the oomphy sense? We can alleviate some doubts by reminding ourselves that essential necessitation is necessity exertion and that production is thus analyzed as the coming about of a fact on account of a necessity that was directly exerted onto that (putative) fact. If there is an even oomphier sense of production, I do not know how that sense could be made explicit. I suggest that the necessity-exertion account of production at least does reasonably well at satisfying our pre-theoretical expectations.

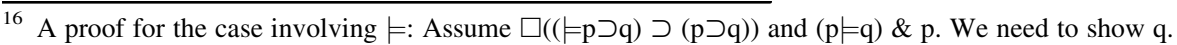
From $\mathrm{p} \models \mathrm{q}$ we can infer $\models p \supset q$, and can then infer $\mathrm{p} \supset \mathrm{q}$ from the assumption. Since we have assumed $\mathrm{p}$ as a conjunct, we can derive q. Hence, $\square(((\mathrm{p} \models \mathrm{q}) \& \mathrm{p}) \supset \mathrm{q})$. Next assume $\square(((\mathrm{p} \models \mathrm{q}) \& \mathrm{p}) \supset \mathrm{q})$ and $\models \mathrm{p} \supset \mathrm{q}$. If we now assume $\mathrm{p}$ and transform $\models \mathrm{p} \supset \mathrm{q}$ into $\mathrm{p} \models \mathrm{q}$, then we can derive $\mathrm{q}$, and hence we get $\mathrm{p} \supset \mathrm{q}$. Thus, we can conclude $\square((\models \mathrm{p} \supset \mathrm{q}) \supset(\mathrm{p} \supset \mathrm{q}))$. If every logical truth $\models \mathrm{r}$ can be brought into the form $\models \mathrm{p} \supset \mathrm{q}$, the sketched proof covers all cases. The proof is more complicated for other explanatory phenomena, as it relies on principles about the transition between monadic and polyadic expressions of a given phenomenon, which I lack the space to discuss here.

${ }^{17} \mathrm{~L}\left({ }_{-},{ }_{-}\right)$could perhaps be defined with the monadic notion $\mathrm{L}\left(\_\right)$along the following lines: $\mathrm{L}(\mathrm{p}, \mathrm{q})$ iff (i) $\mathrm{L}(\varphi)$, (ii) $\mathrm{p}$ and $\mathrm{q}$ are complete world-states, (ii) $\mathrm{p}$ is earlier than $\mathrm{q}$, and (iii) $(\varphi, \mathrm{p}) \models \mathrm{q}$. But one could instead accept the polyadic notion as the more fundamental one.
} 


\section{Production generalized}

Our account of production generalizes to other explanatory phenomena like essence and logical consequence because these other phenomena can also be taken to exert necessity either directly or conditionally. Consider essence first. If essences exert necessity directly, then essences fundamentally establish explanations of the form ' $E(x)(p)$ explains p'. Examples of such explanations include the following:

- You are human because you are essentially human.

- All bachelors are unmarried because that's part of what bachelorhood is. ${ }^{18}$

If, on the other hand, essences exert necessity conditionally, then essences fundamentally establish metaphysical explanations between different facts. To repeat an example of this kind of explanation, Peter's bachelorhood is explained by the fact that Peter is an unmarried male, because it is essential to bachelorhood that if someone is an unmarried male (of appropriate age, etc.) then he is a bachelor.

Essences exercise production governance just in case they exert necessity conditionally. The reasoning for this claim mirrors the analogous reasoning in the case of laws. If essences exert directly, then they fundamentally explain essential truths like 'All bachelors are unmarried'. Metaphysical explanations then follow by subsumption under the explained essential truth and are therefore not productive. So, essences govern in the production sense only if they exert necessity conditionally.

The case of logical consequence is analogous to those of laws and essence. If logical consequence exerts necessity directly, then it fundamentally establishes explanations of logical truths. Examples of such explanations include "It's raining or it's not raining because this is a logical truth."

If, on the other hand, logical consequence exerts conditionally, then logical consequence relationships fundamentally establish logical explanations between different facts. To use examples from the literature on ground, $\mathrm{p}$ logically explains $\mathrm{p}$ $\mathrm{v} \mathrm{q}$, and $\mathrm{p}$ and $\mathrm{q}$ together explain $\mathrm{p} \& \mathrm{q}$, partly because of the logical inferences $\mathrm{p} \models$ $\mathrm{p}$ v q and $\mathrm{p}, \mathrm{q} \models \mathrm{p} \& \mathrm{q}$ (Fine 2012).

Logical consequence exercises production governance just in case it exerts necessity conditionally; it establishes systematizing explanations if it exerts directly. The reasoning for these claims is as before and I won't repeat it. Generalizing this account to all explanatory phenomena, I propose that any phenomenon $\mathrm{S}$ governs in the production sense just in case $\mathrm{S}$ exerts necessity conditionally.

\footnotetext{
18 That you are human is grounded in and thus explained by your biological features, and that all bachelors are unmarried is partly explained by facts about individual bachelors. But these explanations don't compete with the claims made in the text. There are two distinct kinds of explanations for your humanity, one in terms of your biological features and one in terms of your essence. An analogous point applies to explanations of tautologies.

19 Opponents of essence might try using 'It is fundamental that ...' instead of 'it is essential to x that ...'. One problem this proposal faces is that the fundamentality-operator lacks the bearer-position of the essence-operator which serves to identify the exerting phenomenon.
} 
We can also generalize the account of direct and conditional exertion in terms of modal essences. I define that a phenomenon $\mathrm{S}$ exerts necessity directly just in case $\mathrm{S}$ has an essence of the form of Essential Factivity, and $S$ exerts necessity conditionally just in case it has an essence of the form of Essential Polyadic Factivity. ${ }^{19}$ Since production is conditional exertion, it follows from these definitions that production ultimately consists in the modal essence characterized by Essential Polyadic Factivity.

Let me illustrate the account with its application to logical consequence. The modal essences, which determine whether logical consequence is productive or systematizing, are as follows:

$$
\begin{array}{ll}
\text { Essential Factivity }(\vDash) & \mathrm{E}(\vDash)(\square((\vDash \mathrm{P}) \supset \mathrm{P})) \\
\text { Essential Polyadic Factivity }(\vDash) & \mathrm{E}(\models)(\square(((\mathrm{P} \models \mathrm{Q}) \& \mathrm{P}) \supset \mathrm{Q}))
\end{array}
$$

We often express logical consequence with both the monadic notion of logical truth and the polyadic notion of logical entailment. In deciding whether logical consequence systematizes or produces, we also decide which of the two notions is more fundamental or, at any rate, more fundamental to explanation.

It is instructive to see that Essential Polyadic Factivity $(\models)$ is false, given our assumption that necessity exertion suffices for explanation. To see this, consider any non-explanatory entailment like $\mathrm{p} \& \mathrm{q} \models \mathrm{q}$. Since we can read $\mathrm{p} \& \mathrm{q}$ as an instance of $\mathrm{P}$, Essential Polyadic Factivity says that $\models$ exerts necessity on q, conditionally on the premise $\mathrm{p} \& \mathrm{q}$. From this it follows that $\mathrm{p} \& \mathrm{q}$ explains $\mathrm{q}$ because necessity exertion was assumed to suffice for explanation. But this is intuitively the wrong result. We might therefore prefer Essential Factivity $(\models)$ and thus construe logical consequence as non-productive. ${ }^{20}$

\section{Governance analyzed}

I have argued at the outset that "governance" is used in two ways to mean either guidance or production. We can now combine the conclusions of parts I and II to reach the following unified analysis of governance: any phenomenon $\mathrm{S}$ exercises guidance governance just in case $\mathrm{S}$ has a suitable modal essence, and $\mathrm{S}$ exercises production governance just in case $S$ is characterized by Essential Polyadic Factivity. Production governance is therefore a special case of guidance of governance.

My account of governance generalizes beyond laws of nature. This is an advantage of the account for two reasons. First, as I argued in Sect. 4, it is plausible that several explanatory phenomena exercise guidance governance. A suitable account of governance should be sufficiently generality. Secondly, governance is that which enables explanatory phenomena to explain. I have argued that the bearers of

\footnotetext{
${ }^{20}$ We could instead try to save Essential Polyadic Factivity $(\models)$ by using a restricted notion of entailment, or we could deny that logical consequence exerts necessity and thus think of logical explanations as of an altogether different kind.
} 
modal essences exert necessity: to guide is to exert necessity, and to produce is to exert necessity in a particular way. Although I don't claim that this is the only way to establish explanations, I maintain that governing phenomena explain because they exert necessity on facts. They use necessity as their tool for explanation, as their scepter of governance. If correct, the account contributes to the metaphysics of explanation.

The account of governance I have developed is both modal and essentialist. As I have explained in Sect. 8, the account leads naturally to a form of modal primitivism, and production governance requires, in addition, a polyadic construal of the governing phenomenon. These consequences strike me as appropriate costs for a phenomenon that supposedly gives realists an edge over their Humean competitors. I take it to be an advantage of the account that it reveals these costs.

The account, finally, also leaves some questions unanswered. Which phenomena exert guidance governance, and which production governance? Are there perhaps other ways of exerting necessity, and are there different kinds of necessity that are being exerted? And what explains the necessity of the facts pertaining to the explanatory phenomena themselves? I see it as an advantage of the account that it raises these questions, as they allow us to unify the modal-explanatory into a single nexus that awaits further research.

Another set of questions that the account generates is epistemological: how can we determine which kind of governance a given source exerts? There are several epistemic inroads to the productive/systematizing distinction. We might, first, appeal to our senses directly and argue that we 'just see' that certain explanations are productive. We might, secondly, argue on theoretical grounds that certain entities must have productive explanations because they do not precede their own explanation. Arguably, reductive explanations must be productive for that reason. And thirdly, we might get access via the question of whether some explanatory phenomenon is fundamentally monadic or polyadic. For instance, if essence cannot be expressed with a suitable polyadic operator, essentialist explanations are systematizing and not productive. I think it is an advantage of the modal-essentialist account that it raises substantive questions about the kind of governance different phenomena exert and that it contributes to the means of answering them.

\section{Governance through ground?}

The modal-essentialist account I have developed indulges in both essentialist and modal ideology and arguably requires a primitive notion of necessity. But why shouldn't we use a less costly alternative instead? The main competitors to modal accounts identify governance with particular claims involving the notion of metaphysical ground. Gideon Rosen (2010) suggests that L $(\varphi)$ grounds $\varphi$, Harjit Bhogal (2017) suggests that each lawful regularity $\varphi$ grounds its instances, and Nina Emery (2019) proposes that L $(\varphi)$ grounds its instances. Although these accounts have not been developed in detail, ground-based accounts are the main competition.

I lack the space for an in-depth discussion of the different ground-based accounts. But I will raise two general concerns. My first concern is that each of these accounts 
implies controversial claims about ground. Bhogal denies that all regularities are partly grounded in their instances (Bhogal 2017: 454) to maintain the asymmetry of ground, and Emery denies that grounds necessitate the facts they ground (Emery 2019: §7). Rosen's proposal, L $(\varphi)$ grounds $\varphi$, can avoid both of these claims only if we add that $\mathrm{L}(\varphi)$ does not ground the instances of $\varphi$. I do take that version of the ground-based approach to governance to be the most promising.

However, the view that results from Rosen's proposal is an odd picture indeed, as $\varphi$ then has two independent sufficient grounds and laws, therefore, engage in a systematic form of grounding-overdetermination. ${ }^{21}$ This conflicts with Fine's (2012) elimination rule for the sufficient grounds of universal generalizations, which, according to that rule, either include the instances of the regularity or else includes grounds of those instances. That elimination rule is arguably justified by the theoretical benefits of Fine's logic of ground.

Even setting the logic of ground aside, Rosen's proposal conflicts with the view that at least non-vacuous generalizations can be located where its positive instances are. That every perfectly hit window shatters, for instances, seems to be constituted by each of the facts concerning the behavior of hit windows. If we see non-vacuous regularities as "chunks of world" in this way, then it is difficult to see how the regularity could be grounded if not via its constituting instances. The objectual analogue to Rosen's proposal is to ground facts about a statue without 'going via' its constituting matter. I, therefore, doubt that regularities are directly grounded in laws of nature.

All that is not so say that laws do not explain their associated regularities. But this explanatory relation is not ground; it is the kind of explanation, distinctive to laws of nature, that arises when laws of nature exert necessity on facts, or so I suggest. Moreover, I have argued in Sect. 11 that if laws establish productive explanations, their explanation of the regularity proceeds via explanations of instances. But Rosen's proposal establishes a direct link between the law $\mathrm{L}(\varphi)$ and the regularity $\varphi$, and it would be difficult to insert an intermediate step on which some law, L(p, q), and a cause, p, together ground the associated effect, q. For, this view would have the untenable consequence that causes are partial grounds of their effects. (The consequence is untenable as it conflates the contrast between causal and non-causal explanations and as it entails that the world grows less fundamental over time.) An account of governance based on Rosen's proposal would give us guidance governance at best.

In sum, each of the ground-based approaches introduces revisionary claims about ground. And the most promising account, which respects that generalizations are grounded in their instances and also that grounds necessitate, rests on a fairly implausible claim about what grounds what and has difficulties capturing production. This is, of course, not a conclusive argument against ground-based

\footnotetext{
${ }^{21}$ It is an odd kind of overdetermination to boot, as one overdetermining ground, the law, can only ever be an overdetermining sufficient ground, whereas the other one, the instances plus the domain condition (see Fine 2012: §7), can also be the lone sufficient ground of the regularity. This asymmetry might give one the sense that the grounding-work, which laws are supposed to do on the view in question, is idle.
} 
accounts, but I hope to have shown that there is plenty of motivation to opt for the modal-essentialist account instead, despite its metaphysical price tag.

There is, finally, also a more principled reason against basing governance on ground. Ground is a kind of metaphysical explanation, and hence the power to establish relationships of ground is a power to explain. An account of governance should elucidate that power to explain rather than presuppose it. But this is impossible for ground-based accounts, as they identify governance with the power to establish certain grounding explanations. From the point of view of the modalessentialist account, on the other hand, there is nothing special about grounding explanations here: the power to establish grounding explanations can, like the power to establish other kinds of explanation, be accounted for with necessity exertion. ${ }^{22}$

\section{The governance of indeterministic laws}

Finally, one might object that modal accounts of governance do not apply to indeterministic laws, since only deterministic laws (together with sufficient causes) necessitate causal effects; only if the laws are deterministic can we truly say that the perfectly hit window must shatter. If there are genuine indeterministic explanations, one might therefore suspect that their grounding has nothing to do with necessity, let alone with the modal essences of laws.

To clarify, this is not the general challenge of crafting a theory of statistical explanation that features stochastic laws, which in turn are ultimately grounded in deterministic laws. I would be happy to say that, strictly speaking, governance occurs on the more fundamental deterministic level in such cases. (Plus, there are promising theories of such derivative statistical explanations on the market. ${ }^{23}$ ) But what if there are fundamental indeterministic laws? If such genuine indeterminism is coherent, it is also coherent to think of these laws as making the world go 'round, and thus as exerting governance on facts (cf. Maudlin 2007: 176).

The modal-essentialist account can make sense of indeterministic governance in at least the following two ways. The first option is to treat indeterministic laws of nature as having disjunctive contents. Strictly speaking, laws do not generate individual facts in an indeterministic way, but they deterministically produce disjunctions. The law can then be said to help explain the resulting fact $\mathrm{q}$ by helping to determine the disjunction q v r. Such accounts of indeterministic explanation, however, would only allow for guidance governance, as the disjunction that is outputted by the law is crucially involved in grounding the explanation of $\mathrm{q}$, while $\mathrm{q}$ is metaphysically prior to that disjunction. As p ends up metaphysically prior to its own explanation, that explanation cannot be productive. ${ }^{24}$

\footnotetext{
${ }^{22}$ For an account of grounding-explanation, we must first determine which explanatory phenomena establish grounding-explanations. Main candidates include essences (Dasgupta 2016) and metaphysical laws (Wilsch 2015, Glazier 2016). We should ask in what way these phenomena govern.

23 See Hitchcock and Salmon (2001) for an overview.

24 See note 15 for a clarification of this argument and see Pruss (2006: ch. 7-8) for a critical discussion of the disjunction-strategy.
} 
A second way to regard indeterministic laws as necessitating their outputs takes laws to deterministically output chance-facts. Thus, although the laws don't determine (based on some condition $\mathrm{p}$ ) whether $\mathrm{q}$ or $\mathrm{r}$ will obtain next, they do determine that $\mathrm{q}$ has a $70 \%$ chance of obtaining whereas $r$ has a $30 \%$ chance of obtaining, say. We can add the crucial assumption that chances somehow manage to (indeterministically) explain the facts, i.e. that the fact that $\mathrm{q}$ has a $70 \%$ chance explains $q$ (if $q$ obtains) or that the fact that $r$ has a $30 \%$ chance explains $r$ (if $r$ obtains). Indeterministic laws would then govern in the same way as deterministic laws, the difference being that they govern chance-facts rather than 'ordinary' facts.

Neither of these approaches to indeterministic governance is ideal. The first one does not allow for indeterministic production and the second one defers much of what we expect governance to be to the metaphysics of objective chances. But since grounds necessitate, ground-based accounts don't seem to fare any better. I only see one way in which genuine indeterministic governance might be secured in a nonreductive fashion, namely by a sort of quietism about such cases of governance. One might introduce an indeterministic law that takes an input-condition, p, indeterministically to a range of outputs, $q$ and $r$ : L(p; qlr). We then say that this law has a primitive power to explain, namely that when, say, p, L(p; qlr), and r obtain then $\mathrm{p}$ explains $r$ (or $p$ causally determines $r$ ), where the step from law to explanation is not one from truth-conditions to truth, but where the law, the cause and the indeterministic effect form an explanatory nexus, about which (due to the quietist nature of the account) nothing more can be said.

Perhaps this is the best we can do in the case of fundamental indeterminism: laws of nature have a primitive power to explain. But I insist that we should do what we can to analyze this power. As I have argued throughout this article, such an analysis can be given in the deterministic case, and much more would have to be done to show that no progress can be made, along similar lines, in the case of fundamental indeterminism.

\section{Conclusion}

I have attempted in this article to provide a solid theoretic footing for the notion of the governance of the laws of nature. I have argued that to understand that notion we must make two distinctions, the distinction between guidance and production as two kinds of governance, and the distinction between productive and systematizing explanations. I have argued with respect to the first distinction that guidance is a prerequisite for production, and production a special case of guidance. With respect to the second distinction, I have argued that only some guiding phenomena also produce and that it is a substantive question, which phenomena merely systematize.

I have developed a unified account of guidance and production that also generalizes to other explanatory phenomena beyond laws. In the first part of the article, I have analyzed guidance governance in terms of suitable modal essences, which are essences with suitable modal content. There I tried to capture the 
Armstrongean idea that governance is a form of necessity exertion. In the second part, I distinguished two ways in which different guiding phenomena exert necessity, one 'direct' and one 'conditional'. I have tried to show how these ways of exertion can be taken to mark the difference between productive and systematizing explanations, and how they too can be analyzed in modal-essentialist terms. Although I am not sure whether I have successfully defended the account against the major objections, I offer it as one of the most developed accounts of governance to date. $^{25}$

Acknowledgements Open Access funding provided by Projekt DEAL.

Open Access This article is licensed under a Creative Commons Attribution 4.0 International License, which permits use, sharing, adaptation, distribution and reproduction in any medium or format, as long as you give appropriate credit to the original author(s) and the source, provide a link to the Creative Commons licence, and indicate if changes were made. The images or other third party material in this article are included in the article's Creative Commons licence, unless indicated otherwise in a credit line to the material. If material is not included in the article's Creative Commons licence and your intended use is not permitted by statutory regulation or exceeds the permitted use, you will need to obtain permission directly from the copyright holder. To view a copy of this licence, visit http:// creativecommons.org/licenses/by/4.0/.

\section{References}

Armstrong, David. (1983). What is a law of nature? Cambridge: Cambridge University Press.

Beebee, Helen. (2000). The non-governing conception of laws of nature. Philosophy and Phenomenological Research, 61(3), 571-594.

Bhogal, Harjit. (2017). Minimal anti-Humeanism. Australasian Journal of Philosophy, 95(3), 447-460.

Dasgupta, Shamik. (2016). Metaphysical rationalism. Nô̂s, 50(2), 379-418.

Dretske, Fred. (1977). The laws of nature. Philosophy of Science, 44(2), 248-268.

Emery, Nina. (2019). Laws and their instances. Philosophical Studies, 176(6), 1535-1561.

Fine, Kit. (1994). Essence and modality. Philosophical Perspectives, 8(1), 1-16.

Fine, K. (1995). Senses of essence. In W. Sinnott-Armstrong, D. Raffman, \& N. Asher (Eds.), Modality, morality and belief. Essays in honor of Ruth Barcan Marcus (pp. 53-73). New York: Cambridge University Press.

Fine, Kit. (2001). The question of realism. Philosophers' Imprint, 1, 1-30.

Fine, K. (2012). Guide to ground. In F. Correia \& B. Schnieder (Eds.), Metaphysical grounding: Understanding the structure of reality (pp. 37-80). Cambridge: Cambridge University Press.

Glazier, Martin. (2016). Laws and the completeness of the fundamental. In Mark Jago (Ed.), Reality making (pp. 11-37). Oxford: Oxford University Press.

Glazier, Martin. (2017). Essentialist explanation. Philosophical Studies, 174(11), 2871-2889.

Hale, B. (2002). The source of necessity. Nous, 16, 299-319.

Hall, N. (2004). Two concepts of causation. In J. Collins, N. Hall, \& L. Paul (Eds.), Causation and counterfactuals (pp. 225-276). Cambridge: MIT Press.

Hildebrand, Tyler. (2013). Can primitive laws explain? Philosophical Imprint, 13, 1-15.

Hitchcock, C., \& Salmon, W. (2001). Statistical explanation. In W. H. Newton-Smith (Ed.), A companion to the philosophy of science. Hoboken: Wiley-Blackwell.

${ }^{25}$ I owe thanks to Tyler Hildebrand, Martin Lipman, Henrik Rydéhn, Thomas Sattig, Jonathan Schaffer, Markus Schrenk, Erica Shumener, and two anonymous reviewers for this journal for comments and discussions of earlier drafts. The research for this article was supported by a grant from the German Research Foundation. 
Lange, Marc. (2013). Grounding, scientific explanation, and Humean laws. Philosophical Studies, 164(1), 255-261.

Lange, Marc. (2014). Depth and explanation in mathematics. Philosophia Mathematica, 23, 196-214.

Lange, Marc. (2018). Transitivity, self-explanation, and the explanatory circularity argument against Humean accounts of natural law. Synthese, 195(3), 1337-1353.

Lewis, D. K. (1973a). Counterfactuals. Oxford: Blackwell.

Lewis, David K. (1973b). Causation. Journal of Philosophy, 70, 556-567.

Lewis, David K. (1983). New work for a theory of universals. Australasian Journal of Philosophy, 61(4), 343-377.

Lewis, D. K. (1986). Causal explanation. In Philosophical papers (Vol. II, pp 214-240). Oxford University Press.

Loewer, Barry. (1996). Humean supervenience. Philosophical Topics, 24(1), 101-127.

Loewer, Barry. (2012). Two accounts of laws and time. Philosophical Studies, 160(1), 115-137.

Lowe, E. J. (2008). Two notions of being: Entity and essence. Royal Institute of Philosophy Supplement, 62, 23-48.

Marshall, Daniel G. (2015). Humean laws and explanation. Philosophical Studies, 172(12), 3145-3165.

Maudlin, T. (2007). The metaphysics within physics. Oxford: Oxford University Press.

Miller, Elizabeth. (2015). Humean scientific explanation. Philosophical Studies, 172(5), 1311-1332.

Pruss, A. (2006). The principle of sufficient reason: A reassessment. Cambridge: Cambridge University Press.

Rosen, G. (2010). Metaphysical dependence: Grounding and reduction. In B. Hale \& A. Hoffmann (Eds.), Modality: Metaphysics, logic, and epistemology (pp. 109-136). New York: Oxford University Press.

Schaffer, Jonathan. (2004). Of ghostly and mechanical events. Philosophy and Phenomenological Research, 68(1), 230-244.

Schaffer, Jonathan. (2016). It is the business of laws to govern. Dialectica, 70(4), 577-588.

Sider, Theodore. (2012). Writing the book of the world. New York: Oxford University Press.

Skow, Bradford. (2016). Reasons why. Oxford: Oxford University Press.

Wilsch, Tobias. (2015). The nomological account of ground. Philosophical Studies, 172(12), 3293-3312.

Wilsch, Tobias. (2017). Sophisticated modal primitivism. Philosophical Issues, 27(1), 428-448.

Wilsch, Tobias. (2018). Genuine violations of laws. Australasian Journal of Philosophy, 96(4), 806-821.

Publisher's Note Springer Nature remains neutral with regard to jurisdictional claims in published maps and institutional affiliations. 